\title{
Aging and memory for faces versus single views of faces
}

\author{
JAMES C. BARTLETT and JO E. LESLIE \\ The University of Texas at Dallas, Richardson, Texas
}

\begin{abstract}
Differences in the ability of young adults and elderly to recognize faces were examined under two conditions. In a standard single-view condition, in which each input face was shown as one photograph, we confirmed prior findings that young adults perform better than the elderly at distinguishing photographs seen before from photographs of new faces. We also found that the elderly had more trouble distinguishing photographs seen before from photographs of (1) old faces changed in facial expression and (2) old faces changed in expression and pose. Yet there were no reliable age differences in distinguishing old-but-changed faces from entirely new faces. In a more naturalistic multi-view condition, in which each input face was shown in four poses and with two expressions, no age differences were found. A second experiment ruled out the possibility that varied repetition, by itself, removes age differences in recognizing faces. These data sup. ported age differences in remembering facial expressions and possibly other details of photographs of faces, but not in remembering faces per se.
\end{abstract}

Young adults perform better than elderly adults in a variety of long-term memory tasks (Craik, 1977). Furthermore, although most relevant studies have used verbal materials, a growing literature reports adult age differences in remembering nonverbal stimuli, such as voices, bird songs, abstract designs, tactile shapes, and pictures of objects and scenes (e.g., Kausler \& Puckett, 1981; Riege \& Inman, 1981; Till, Bartlett, \& Doyle, 1982), as well as spatial information (Bartlett, Till, Gernsbacher, \& Gorman, 1983; Light \& Zelinski, 1983; Park, Puglisi, \& Sovacool, 1983; Pezdek, 1983). The present experiment extends two prior studies that showed age differences in recognizing pictures of faces (Ferris, Crook, Clark, McCarthy, \& Rae, 1980; Smith \& Winograd, 1978). In both of these prior studies, hits to identical copies of previously viewed items were similar for young and elderly groups, but false alarms to new items were higher among the elderly, supporting an age difference in identical/new discrimination. The size of this age difference appeared unrelated to the elderly subjects' educational backgrounds (Smith \& Winograd, 1978), and even to their diagnosed status as demented versus normal (Ferris et al., 1981). Thus, an effect of "normal aging", was suggested.

Despite respectably large literatures both on aging and memory and on basic processes of face recognition (Davies, Ellis, \& Shepherd, 1981), age differences in distinguishing photographs seen before from photographs of new faces pose something of a puzzle. Although there are documented age differences in memorization strategies

We thank C. J. Brainerd, Valerie Reyna, David Mitchell, and W. J. Dowling for valuable discussions, and R. Klatzky and two anonymous reviewers for perceptive comments on an earlier draft of this article. The research was supported by Organized Research Funds from the University of Texas System. Requests for reprints should be sent to James C. Bartlett, Programs in Psychology and Human Development, The University of Texas at Dallas, Box 688, Richardson, TX 75080
(Perlmutter \& Mitchell, 1982), Smith and Winograd (1978) found age differences in face recognition not only in an intentional learning condition, in which subjects viewed input faces in expectation of a test, but also in incidental learning conditions, in which no test was expected. On the assumption that incidental learning conditions reduce the importance of memorization strategies (see Guttentag, 1985), such strategies probably do not underlie the observed age differences in face memory. Another possible source of age differences in memory is a confounding between age and familiarity of stimuli and/or practice on a memory task (Rogoff, Gauvain, \& Ellis, 1984). But faces are obviously quite familiar kinds of stimuli, and an active individual continues learning new faces throughout his/her life. A third source of age differences in "visual" memory tasks is verbal coding (e.g., Bartlett, Till, \& Levy, 1980; Pezdek \& Evans, 1979): young adults might engage in verbal coding to a greater extent than elderly adults (Arenberg, 1977). However, faces are notoriously difficult to verbalize, and several studies have failed to find evidence that verbal coding skills or verbal coding strategies are significantly related to face-memory performance (Bartlett, Hurry, \& Thorley, 1984; Chance \& Goldstein, 1976; Goldstein, Johnson, \& Chance, 1979).

Although these reasonable accounts of age deficits in memory are questionable in the face-memory domain, an additional and possibly more viable account is suggested by a study by Yarmey and Kent (1980) on eyewitness identification. Young-adult and elderly subjects viewed a slide sequence depicting a simulated crime and later attempted to identify the assailant, the victim, the victim's companion, and a bystander in a recognition test. As compared with the data from the previously cited studies by Smith and Winograd (1978) and Ferris et al. (1980), the evidence for age differences in the Yarmey and Kent study was slight. Although the young surpassed the elderly in 
correctly identifying the bystander as "old," there were no differences between the two groups in identifying the assailant, victim, or victim's companion as "old," or in identifying new faces as "new."

In interpreting their findings, Yarmey and Kent (1980) suggested,

It is possible that the elderly, in contrast to the young, reduced their cognitive work by attending primarily to central details of episodes, whereas conceptually unimportant events such as bystanders to the crime were selectively ignored and were not thematically integrated into the criminal incident. (p. 367)

Similar ideas, advanced under the banner of a "contextualist" perspective (Labouvie-Vief \& Schell, 1982; Poon, 1985), have received some support in studies of memory for meaningful prose passages (Zelinski, Gilewski, \& Thompson, 1980). Although the evidence is not entirely consistent (see Cohen, 1979; Petros, Tabor, Cooney, \& Chabot, 1983), "it has been suggested that, with aging, there is an adaptive trade-off of low structured detail for higher-ordered units of meaning"' (Poon, 1985, p. 444).

Our goal in the present research was to test further an adaptive-trade-off hypothesis for age effects and noneffects in various face-memory tests. There were many differences between (1) the Smith and Winograd (1978) and Ferris et al. (1980) studies, in which age differences were robust, and (2) the Yarmey and Kent (1980) study, in which general age differences were absent with most measures. However, perhaps the most important difference was that the former studies used standard laboratory procedures for testing face memory, procedures in which the input faces were shown as single photographs and the test faces either were identical copies of previously viewed photographs of faces or were entirely new stimuli. Such procedures are artificial in that when a person experiences a face in ordinary life, he/she views it from different angles (different poses) and watches it go through various movements (different expressions). Moreover, we generally do not subsequently see the face in precisely the same form (Bruce, 1983; Gibson \& Spelke, 1983; Hay \& Young, 1982). Hence, the standard laboratory task is one of face-picture recognition, or "stimulus recognition" (Hay \& Young, 1982), as opposed to face recognition per se.

The difference between face recognition and facepicture recognition is not just naturalism or verisimilitude to "real life." This difference involves the types of face information that might be remembered and used in recognition. This point can be clarified based on Klatzky's (1983a; Klatzky \& Forrest, 1984) conception that internal representations for faces in memory consist of components that vary in abstraction (i.e., in the size of the set of face stimuli that these representations match). By this view, the standard face-recognition measure of identical/new discrimination might reflect retrieval of a variety of components. Although all components contributing to identical/new discrimination must "match" identical-copy items and "mismatch" new faces, they nonetheless might vary along a continuum of abstraction from (1) concrete, "view-specific" components that match one or a few views of a face but mismatch most others of that same face, to (2) more abstract, "facespecific" (but not view-specific) components that match many differing views of a face but mismatch views of (most) other faces. Although many face-memory components might fall between these two endpoints, it is convenient for expository purposes to contrast view-specific components-that is, those that are closer to the viewspecific endpoint-with face-specific components-that is, those that are closer to the face-specific endpoint (Bruce, 1983, makes a similar distinction between "pictorial" and "structural" codes.) Whereas the former components capture concrete details, such as expression and pose, the latter capture more abstract features or "invariants" that are relatively constant across changes in expression and pose.

We note that there may be face-memory components that are still more abstract than face-specific components (e.g., components corresponding to race and age designations). However, components of this degree of abstraction will generally match many new faces as well as old faces, which would minimize their effects on identical/new discrimination (see Klatzky, Martin, \& Kane, 1982). Hence, they are unlikely to be implicated in age differences in identical/new discrimination. We also note that the view-versus-face-specific dimension is one of abstraction, as opposed to representational format or processing "depth." For example, we make no assumption in this paper that the more concrete components are necessarily visual or "literal," and that the more abstract components are necessarily semantic or conceptual (see Klatzky, $1983 \mathrm{~b}$, for discussion of these concepts).

Given the componential framework suggested by Klatzky (1983a), an adaptive-trade-off hypothesis can be formulated as follows: Aging involves various processing slowdowns (Salthouse, 1980) and inefficiencies (Perlmutter, 1980) that produce a tendency, perhaps unconscious, to selectively encode relatively abstract components (those near the face-specific endpoint) at the expense of more concrete components (those near the view-specific endpoint). This trade-off can be viewed as ecologically adaptive, since in most real-life situations of recognizing faces, it appears quite likely that highly concrete, view-specific components are relatively unimportant. First, due simply to interfering effects of originally experiencing a large number of poses and expressions, view-specific components are probably simply irretrievable, regardless of age, in many real-world situations. Second, because of changes in a face between "encoding" and "test," view-specific features are unlikely to aid subjects in recognizing a face as familiar. In contrast, in laboratory tasks of face-picture recognition, in which highly concrete, view-specific components can contribute to the dependent measure (identical/new discrimination), an elderly subject's tendency to minimize encoding of view-specific components can produce a memory deficit. 


\section{EXPERIMENT 1}

Our aim in this study was to test two predictions of the idaptive-trade-off hypothesis. The first prediction was that ige differences in face recognition would be generally arger under standard laboratory conditions of single-view Jresentation, in which each input face is shown as a sinyle photograph, than under more naturalistic conditions of multi-view presentation, in which each input face is shown as a sequence of several photographs. The second rediction was that, in the single-view-presentation conlition, age differences should be larger with measures senitive to view-specific components than with measures iensitive to face-specific components.

In order to test these two predictions, we showed half If the subjects an input list that contained just one photoyraph per face, whereas the remainder of the subjects were hown a list that contained four different photographs per ace. The four views of each face included four different oses and two facial expressions, as shown in Figure 1a. The subsequent test of recognition memory included three Jasic classes of item: (1) identical copies of input items, 2) entirely new items, and (3) old items changed in faial expression or in both facial expression and pose Figure 1b). Subjects' recognition judgments (see Procelure and Results sections) allowed us to examine, within sach age group and input condition, signal-detectionheory measures of three basic types: (1) identical-versuslew discrimination, (2) changed-versus-new discriminaion, and (3) identical-versus-changed discrimination.

Our assumptions and predictions regarding these meaiures are summarized in Table 1. As shown in the table, ve assumed that in the single-view condition, identi:al/new discrimination would be sensitive to both faceipecific and view-specific components, whereas in the nulti-view condition, in which view-specific components ihould have low retrievability, identical/new discriminaion was expected to reflect primarily face-specific comsonents. Hence, age differences in identical/new discrimisation were predicted in the single-view condition, but lot in the multi-view condition.

Regardless of input condition, changed/new discrimilation was assumed to be sensitive primarily to facepecific components and, therefore, to show minimal age lifferences. However, prior findings of Dukes and Bevan 1967) led us to expect that changed/new discrimination vould be increased by multi-view presentation, presumahy due to improved retrieval of face-specific components.

Identical/changed discrimination was assumed to be ased on view-specific components and, therefore, to how age differences. However, this prediction was made inly for the single-view condition. The multi-view conlition was expected to produce low retrievability of viewpecific components and, therefore, to show floor effects vith the identical/changed measures.

Several additional aspects of this study should be noted. Jur use of two types of old-but-changed faces-changedxpression faces and changed-expression-and-pose
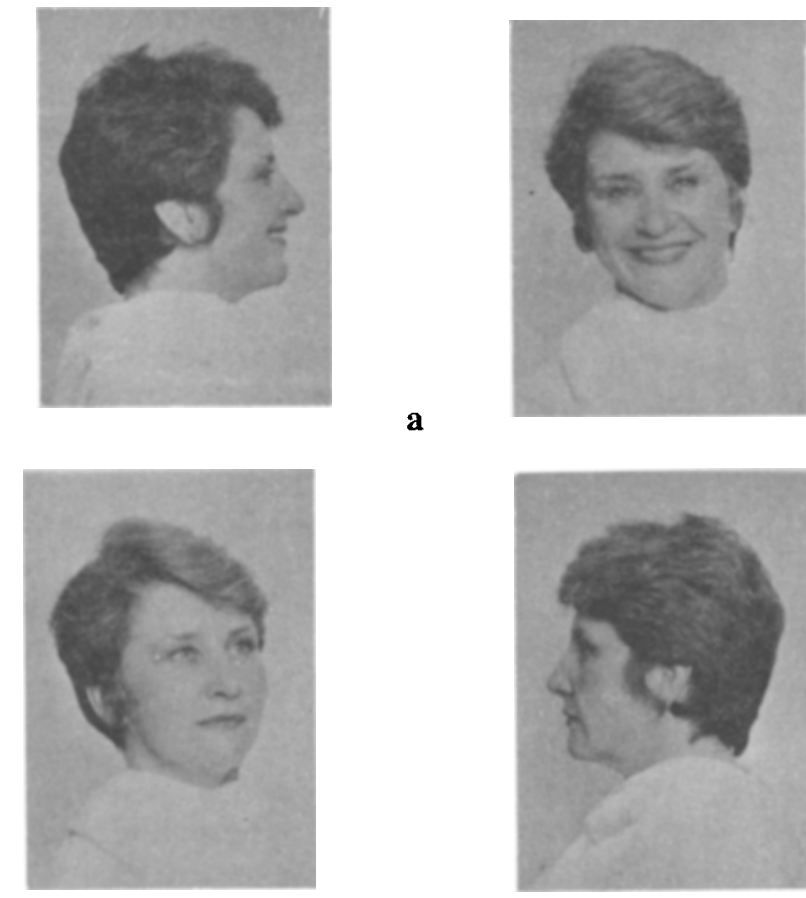

$\mathbf{a}$
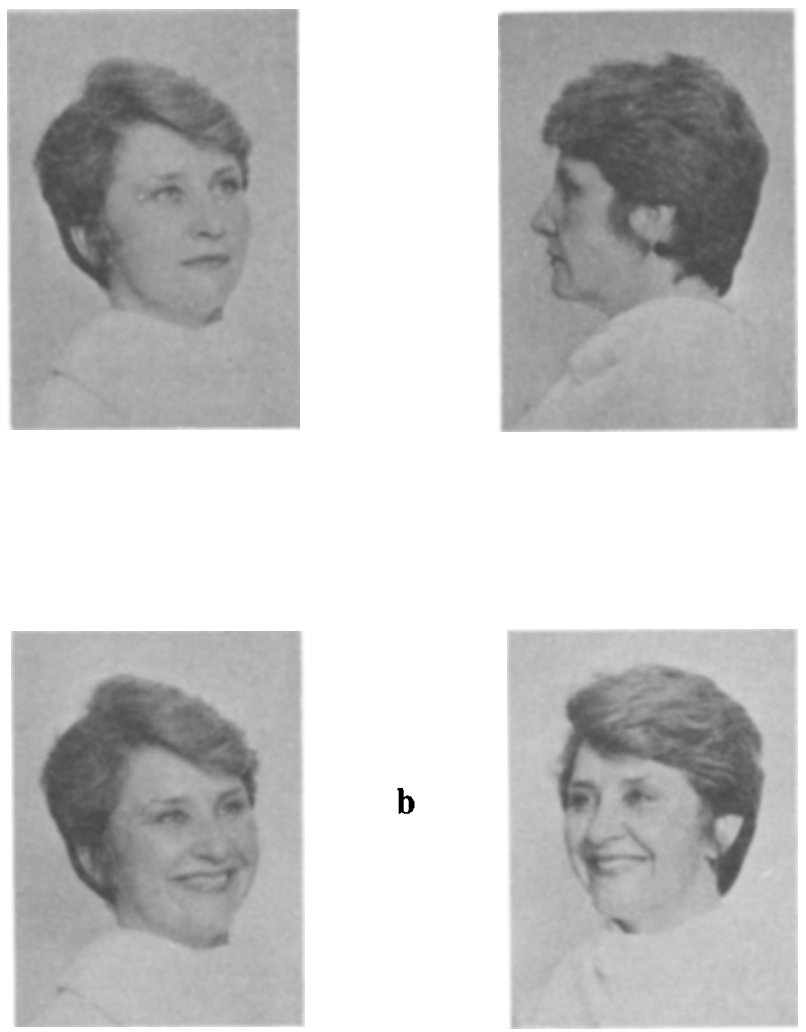

Figure 1. The top four pictures (a) show four views of an input face used in the multi-view condition. The presentation order was right-profile-smiling, right-three-quarters-neutral, frontal-smiling, and left-profile-neutral. In the single-view condition, only the rightthree-quarters-neutral view was shown. The lower two pictures (b) are a changed-expression item (left) and a changed-expressionand-pose item (right) used in recognition.

faces-was based on findings (Bruce, 1982) that two changes in a face can affect recognition more than a single change. Although we did not expect these two item types to differ qualitatively, they allowed us to examine age effects at two different levels of task performance. In order to minimize special strategies (e.g., verbalization) for memorizing faces or aspects of faces, we used an incidental learning task, that of rating input faces for pleasantness. This task (1) was similar to the friendlinessrating task used by Smith and Winograd (1978), (2) was known to produce high face-memory performance (War- 
Table 1

Discrimination Measures, Hypothesized Components Contributing to These Measures, and Predicted Age Differences for Experiment 1

\begin{tabular}{cccl}
\hline & \multicolumn{4}{c}{ Type of Component and Prediction } \\
\cline { 2 - 4 } $\begin{array}{c}\text { Measure } \\
\text { and Condition }\end{array}$ & $\begin{array}{c}\text { View- } \\
\text { Specific }\end{array}$ & $\begin{array}{c}\text { Face- } \\
\text { Specific }\end{array}$ & $\begin{array}{l}\text { Age } \\
\text { Difference? }\end{array}$ \\
\hline Identical/New & & & \\
Single-View & + & + & Yes \\
Multi-View & - & + & No \\
Changed/New & & & \\
Single-View & - & + & No \\
Multi-View & - & + & No \\
Identical/Changed & & & \\
Single-View & + & - & Yes \\
Multi-View & - & - & No* \\
\hline
\end{tabular}

Note-A "+" indicates that a memory component contributes to a measure, and a "-" indicates that it does not. The multi-view condition was expected to increase retrievability of face-specific components but to decrease retrievability of view-specific components virtually to zero. *Floor effects expected.

rington \& Ackroyd, 1975), and (3) allowed a check on subjects' noticing of expression at input (smiling faces were expected to be rated more pleasant). Also, in an attempt to minimize the use of memorization strategies, we used high-school seniors instead of "experiment-wise" undergraduate psychology majors as our young subjects (in Experiment 2, we used nonstudents in their 20s and early $30 \mathrm{~s}$ ). It is sometimes observed that females surpass males in face-memory performance (Shepherd, 1981), perhaps especially with female faces (McKelvie, 1981). Wanting to examine face memory under optimal conditions, we restricted ourselves to female subjects and faces. Finally, due to possible age of subject $\times$ age of face interactions, we followed Smith and Winograd (1978) in using faces covering a range of adult ages.

\section{Method}

Subjects. The 36 young subjects were female seniors in a Catholic high school in Dallas, Texas. The 33 elderly subjects were female volunteers in (self-reported) good health who were recruited from church groups and residential communities for the elderly in Dallas. All but 1 of the elderly were high school graduates, and 8 had college degrees. All young subjects were 18 years old, whereas the average age of the elderly subjects was 74.2 years $(S D=6.8)$. A criterion for inclusion in the study was (corrected) visual acuity of $20 / 40$ or better in the best eye (preliminary analyses suggested no effect of acuity on face-memory performance within the restricted range of 20/20 to 20/40). Average vocabulary (second half of the WAIS) was 16.8 out of $40(S D=5.5)$ in the young group versus 23.3 out of $40(S D=9.2)$ in the elderly group, representing a significant advantage of the elderly sample on this verbal intelligence measure $[t(67)=3.58, p<.01] .^{1}$

Materials. The stimulus materials were $35-\mathrm{mm}$ color photographic transparencies of 72 faces of women in their $20 \mathrm{~s}(19 \%)$, $30 \mathrm{~s}(33 \%)$, $40 \mathrm{~s}(25 \%)$, and $50 \mathrm{~s}, 60 \mathrm{~s}$, and $70 \mathrm{~s}(22 \%)$. The age distribution for the 48 input items was similar to that for the 24 recognition-test lures. Each face was photographed in five different poses (both profiles, both three-quarter views, and the frontal view), and with two expressions (smiling and neutral), for a total of 10 photographs per face. All photographs were made with glasses and jewelry removed from the face and with clothing obscured by a white sheet draped over the shoulders.

The input list for the multi-view condition included 48 to-beremembered faces, with four photographs per face. Subsets of 12 faces were assigned to each of four different presentation-types, defined by the factorial combination of two expression sequences (smile/neutral/smile/neutral vs. neutral/smile/neutral/smile) and two pose sequences (right-profile/right-three-quarters/frontal/left-profile vs. right-profile/frontal/left-three-quarters/left-profile). Note that each face was shown in either the left- or right-three-quarters pose, and that it was either smiling or neutral when in that pose. Of course, across the four poses, all faces were shown with both smiling and neutral expressions and in the frontal and both profile views as well as in one three-quarters view. An example of a four-pose sequence is shown in Figure 1.

The input list for the single-view condition was identical to that of the multi-view condition, but with all frontal and profile views omitted. This left one photograph per face: a right-three-quarterssmiling, right-three-quarters-neutral, left-three-quarters-smiling, or left-three-quarters-neutral view (12 faces shown with each type of view).

The recognition test was identical in the multi-view and singleview conditions. It included 48 old (input) faces intermixed with 24 new faces, all shown in a three-quarters pose. The 24 new items included 6 right-three-quarters-smiling views, 6 right-three-quartersneutral views, 6 left-three-quarters-smiling views, and 6 left-threequarters neutral views. The 48 old items included 16 identical copies of input items, 16 changed-expression items, and 16-changedexpression-and-pose items. Each of the 16 changed-expression items was shown in the same (right or left) three-quarters-pose used at input, but with the expression changed (smiling to neutral or vice versa). Each of the 16 changed-expression-and-pose items was shown in the opposite three-quarters pose, and with expression changed from that of the input three-quarters pose. For example, if the input three-quarters view was right-three-quarters-neutral, a changed-expression item would be right-three-quarters-smiling, and a changed-expression-and-pose item would be left-threequarters-smiling. Figure 1 (bottom) includes an example of each type of changed-view item.

For counterbalancing purposes, we prepared three versions of the recognition test and used each with approximately one third of the subjects from each age group. Across these three versions, each input face was tested as an identical item, a changed-expression item, and a changed-expression-and-pose item.

Design and Procedure. The between-subjects variables were age of subject (young vs. elderly) and input condition (single-view vs. multi-view). The within-subjects variable was item type in recognition (identical, changed-expression, changed-expression-and-pose, and new items).

Each experimental session included 1 to 6 subjects. The subjects began by filling out a general information sheet (providing data on age, education, and any health-related problems) and then had their vision tested with a Snellen chart. The vision test was followed by a 20 -item vocabulary test (the second half of the WAIS vocabulary test), for which $10 \mathrm{~min}$ were allowed. Immediately after the vocabulary test, all subjects were told that we were interested in how different age groups perceive and interpret the female face. They were not forewarned of a memory test.

The instructions for the multi-view condition were that a sequence of faces would be presented, and that the task was to rate each face for pleasantness using a $1-$ to- 5 scale $(1=$ most pleasant $)$. Subjects were told that there were four different photographs of each face, and that all four should be viewed before making a pleasantness rating. They were asked to look at each photograph for its entire duration, and to make their ratings only during the "blank" intervals that followed each set of four photographs (i.e., each face). 
Table 2

Mean Proportions of "Old" and "Same" Judgments to Identical, Changed-Expression, Changed-Expression-and-Pose, and New Items in Each Experimental and Age Group of Experiment 1

\begin{tabular}{|c|c|c|c|c|c|c|c|c|}
\hline \multirow[b]{2}{*}{$\begin{array}{l}\text { Condition } \\
\text { and Age }\end{array}$} & \multicolumn{4}{|c|}{ "Old" Judgments* } & \multicolumn{4}{|c|}{ "Same" Judgments } \\
\hline & Identical & $\begin{array}{l}\text { Changed } \\
\text { Expression }\end{array}$ & $\begin{array}{c}\text { Changed } \\
\text { Expression-Pose }\end{array}$ & New & Identical & $\begin{array}{l}\text { Changed } \\
\text { Expression }\end{array}$ & $\begin{array}{c}\text { Changed } \\
\text { Expression-Pose }\end{array}$ & New \\
\hline \multicolumn{9}{|c|}{ Single-View } \\
\hline Young & .97 & .85 & .66 & $.29 \dagger$ & .66 & $.27 \dagger$ & $.09+$ & $.03 \dagger$ \\
\hline Elderly & .91 & .84 & .70 & $.41 \dagger$ & .49 & $.33 \dagger$ & $.14 \dagger$ & $.09 \dagger$ \\
\hline \multicolumn{9}{|l|}{ Multi-View } \\
\hline Young & .84 & .79 & .76 & $.22 \dagger$ & .44 & $.39+$ & $.29 \dagger$ & $.03 \dagger$ \\
\hline Elderly & .88 & .86 & .78 & $.35 \dagger$ & .45 & $.36 \dagger$ & $.32 \dagger$ & $.06 \dagger$ \\
\hline
\end{tabular}

*Subjects classified each test item as "same," "old-but-different," or "new." The proportions of "old" judgments shown in this table were derived by subtracting the proportions of "new" judgments from 1. fProportions are false-alarm rates. All other proportions are hit rates.

Subjects indicated their ratings by checking appropriately numbered columns on response sheets.

The instructions for the single-view condition were similar, except that subjects were told that each face would be shown as a single photograph. Subjects were asked to look at each photograph for its entire duration, and to make their ratings only during the intervals that followed each photograph (face).

In both the multi-view and single-view conditions, each input face was shown for $12 \mathrm{sec}$, and was followed by $3 \mathrm{sec}$ of "blank" time. However, the nature of a face's 12 -sec presentation varied between conditions. In the multi-view condition, this $12-\mathrm{sec}$ presentation consisted of a succession of four 3-sec presentations of different photographs of the same face. In the single-view condition, this 12 -sec presentation consisted of continuous display of just one photograph.

Immediately after the input list, all subjects were told that they would view another list of pictures, including identical copies of previously viewed pictures, pictures of old faces changed in expression only or in both expression and pose, and pictures of new faces. An example of each item type was shown and discussed. Subjects were instructed to judge each test picture as "exactly the same", (identical), "old-but-different" (changed-expression or changedexpression-and-pose), or "new," and to respond by checking one of three columns on a response sheet. Each test face was shown for $10 \mathrm{sec}$, and was followed by $3 \mathrm{sec}$ of response time.

\section{Results}

The overall proportions of correct recognition judgments averaged .63 and .54 for young and elderly subjects in the single-view condition $[t(32)=2.88, p<.01]$, and .52 and .52 for young and elderly subjects in the multi-view condition. Although this pattern is consistent with predictions, a problem with the proportion-correct measure is that chance performance depends on response bias (a subject who classified all items as being "old-butdifferent" would score $44 \%$ correct, whereas one who classified all items as being "same" would score $22 \%$ correct). Furthermore, it is unanalytical regarding the information (view- or face-specific) that subjects might have used. Hence, all subsequent analyses are based on nonparametric $A^{\prime}$ scores (Grier, 1971) indexing discrimination-separate from response bias-between various item types (the parametric $d^{\prime}$ index revealed the same pattern). An $\alpha$ level of .05 was used for all subsequent statistical tests.

The hit and false-alarm rates used to compute the $A^{\prime}$ 's were proportions of "same" judgments and proportions of "old" judgments (i.e., 1 minus proportions of "new" judgments) to various item types. The means of the various hit and false-alarm rates are shown in Table 2, where (1) age differences in "old"-judgment proportions appear larger with new items than with other item types (cf. Smith \& Winograd, 1978; Ferris et al., 1980), and (2) age differences in "same"-judgment proportions are evident in the single-view condition, but not in the multi-view condition. The age differences as well as effects of condition are clarified by $A^{\prime}$ analyses.

Identical/new discrimination. The identical/new $A^{\prime}$ scores in Table 3 were computed in two ways: (1) using "old" judgments to identical items as hits versus "old" judgments to entirely new items as false alarms, and (2) using "same" judgments to identical items as hits versus "same" judgments to entirely new items as false alarms. Although these two $A^{\prime}$ measures were only moderately correlated $(r=.50)$, they both showed stronger age differences in the single-view condition than in the multiview condition. An analysis of variance (ANOVA) performed on both measures revealed a main effect for type of measure $[F(1,65)=9.30, \mathrm{MSe}=.003$ ("old"judgment $A$ 's slightly exceeding "identical"-judgment $A^{\prime}$ s) and age $[F(1,65)=10.9, M S e=.007(A$ 's for young subjects exceeding those for the elderly)], as well as an age $\times$ experimental condition interaction $[F(1,65)=$ 5.63, MSe $=.007] .^{2}$

Changed/new discrimination. Table 4 shows means of two changed/new $A^{\prime}$ scores, which were based on the proportions of "old" judgments to (1) changed-

Table 3

$A^{\prime}$ 's for Identical/New Discrimination Based on "Old" and "Same" Judgments in Each Age and Experimental Group of Experiment 1

\begin{tabular}{lcc}
\hline & \multicolumn{2}{c}{ Basis of Computation } \\
\cline { 2 - 3 } Condition and Age & "Old" Judgments & "Same" Judgments \\
\hline Single-View & \multicolumn{2}{c}{} \\
Young & .92 & .90 \\
Elderly & $.84 *$ & $.81^{*}$ \\
Multi-View & & \\
Young & .88 & .83 \\
Elderly & .85 & .83 \\
\hline
\end{tabular}

*Age difference significant by $t$ test $(p<.01)$. 
expression versus new items and (2) changed-expressionplus-pose versus new items. An ANOVA performed on these two measures (correlated at $r=.63$ ) showed a main effect for type of discrimination $[F(1,65)=37.7, M S e$ $=.003$ (changed-expression/new discrimination gave generally higher scores)], a main effect for condition $[F(1,65)=7.37, M S e=.013$ (the multi-view condition gave generally higher scores)], and a condition $\times$ type of discrimination interaction $[F(1,65)=11.6, M S e=$ .003]: The multi-view condition exceeded the single-view condition in changed-expression-and-pose/new discrimination (.83 vs. .74), and also, but to a much lesser extent, in changed-expression/new discrimination (.85 vs. .83 ). Thus, changed/new discrimination, at least with changed-expression-and-pose items, was improved in the multi-view condition. There were no effects involving age, however $(p s>.10)$.

Identical/changed discrimination. Table 5 displays means of two identical/changed discrimination scores, which were based on proportions of "same" judgments to (1) identical versus changed-expression items, and (2) identical versus changed-expression-and-pose items. An ANOVA performed on these two measures (correlated at $r=.62$ ) supported main effects for type of discrimination $[F(1,65)=34.7, M S e=.008$ (identical/changedexpression-and-pose higher than identical/changedexpression)], experimental condition $[F(1,65)=49.9$, $M S e=.019$ (single-view better than multi-view)], and age $[F(1,65)=4.55, M S e=.019$ (young better than elderly)]. There also was an age $\times$ condition interaction $[F(1,65)=6.71, M S e=.019]$, which was qualified by an age $\times$ condition $\times$ type of discrimination interaction $[F(1,65)=4.06, M S \mathrm{e}=.008]$. In view of possible floor effects in the multi-view condition (chance $A^{\prime}=.50$ ), an appropriately conservative interpretation of this pattern is that view-specific recognition showed an age-related deficit in the single-view condition, and was generally low in both age groups in the multi-view condition.

In summary, although identical-new discrimination showed no main effect for experimental condition, it did show age differences in the single-view condition but not in the multi-view condition. Changed/new discrimination was improved in the multi-view condition, especially with changed-expression-and-pose items but it showed no reliable age effects. Identical-changed discrimination was im-

Table 4

$A$ 's for Changed-Expression/New and Changed-Expression-and-Pose/New Discrimination in Each Age and Experimental Group of Experiment 1 Type of Discrimination

\begin{tabular}{|c|c|c|}
\hline \multirow[b]{2}{*}{$\begin{array}{l}\text { Condition } \\
\text { and Age }\end{array}$} & \\
\hline & $\begin{array}{c}\text { Changed-Expression/ } \\
\text { New }\end{array}$ & $\begin{array}{c}\text { Changed-Expression-Pose } \\
\text { New }\end{array}$ \\
\hline \multicolumn{3}{|l|}{ Single-View } \\
\hline Young & .86 & .77 \\
\hline Elderly & .80 & .72 \\
\hline \multicolumn{3}{|l|}{ Multi-View } \\
\hline Young & .85 & .84 \\
\hline Elderly & .85 & .82 \\
\hline
\end{tabular}

Note-No age difference was reliable by $t$ test $(p s>.05$ ).
Table 5

$A$ 's for Identical/Changed-Expression and Identical/Changed-Expression-and-Pose Discrimination in Each Age and Experimental Group of Experiment 1

\begin{tabular}{lcc}
\hline \multirow{2}{*}{$\begin{array}{c}\text { Condition } \\
\text { and Age }\end{array}$} & $\begin{array}{c}\text { Tdentical/Changed } \\
\text { Expression }\end{array}$ & $\begin{array}{c}\text { Tdentical/Changed } \\
\text { Expression-and-Pose }\end{array}$ \\
\cline { 2 - 3 } $\begin{array}{c}\text { Single-View } \\
\text { Young }\end{array}$ & .78 & .87 \\
Elderly & $.64^{*}$ & $.78^{*}$ \\
Multi-View & & \\
Young & .54 & .64 \\
Elderly & .59 & .62 \\
\hline
\end{tabular}

*Age difference in $\mathrm{A}^{\prime}$ significant by $t$ test $(p<.01)$.

paired in the multi-view condition, and it also showed age effects in the single-view condition where it was above the floor. We note that the same pattern shown by identi$\mathrm{cal} /$ changed $A$ 's was also shown by probabilities of correct "identical" and "old-but-different" decisions, given recognition that items were "old" (i.e., given that they were not judged "new"). The means of these conditional probabilities were .75 for the young-single-view group, .65 for the elderly-single-view group, .55 for the youngmulti-view group, and .56 for the elderly-multi-view group (chance $=.50$ ). The age $\times$ condition interaction was reliable $[F(1,65)=6.44, M S e=.022]$.

Age-of-face effects. For exploratory purposes, we (1) dichotomized our faces into "young" (20s and 30s) and "old" (40s through 70s) categories, (2) computed $A$ ' scores for the faces in each category, and (3) performed a set of ANOVAs adding face-age as a variable. Although ANOVAs of identical/new and identical/changed $A$ 's revealed no effects involving face-age, the ANOVA of changed/new $A^{\prime}$ s showed a face-age main effect $[F(1,65)$ $=7.47, M S e=.013]$, a face-age $\times$ subject-age interaction $[F(1,65)=10.03, M S e=.013]$, and a face-age $\times$ subject-age $\times$ condition $\times$ measure interaction $[F(1,65)$ $=5.62, M S \mathrm{e}=.008]$. To clarify this pattern, we performed separate ANOVAs of the young- and elderlysubject data. The young-subject ANOVA showed an effect of face-age $[F(1,34)=14.0, M S e=.017]$, with no interactions involving that variable: Mean $A^{\prime}$ 's were .87 and .79 for young and old faces, respectively. The elderlysubject ANOVA showed no reliable effects involving faceage: Mean $A^{\prime}$ s here were .80 and .81 for young and old faces, respectively. Experiment 2 sheds more light on effects of the face-age variable.

\section{Discussion}

The adaptive-trade-off hypothesis for age differences in face memory made two predictions for the outcome of this study. The first prediction was that we would replicate the finding of age differences in the single-view condition, and find relatively small or even no age differences in the multi-view condition. This prediction was supported by the proportion-correct analysis, and also by the $A^{\prime}$ scores. Reliable age differences were found with some of the $A^{\prime}$ measures (identical/new and identi$\mathrm{cal} /$ changed) in the single-view condition, but not with 
any $A^{\prime}$ measure in the multi-view condition. We note that iveraging all six of the $A^{\prime}$ measures produced overall scores of .85 and .77 for young and elderly subjects in the single-view condition $[t(32)=3.50, p<.01]$, and .76 and .76 for young and elderly subjects in the multiview condition.

The second prediction of the adaptive-trade-off hypothesis was that within the single-view condition, age differences in identical/new discrimination, which had been observed in prior research, would be replicated here and also would generalize to identical/changed discrimination, but not to changed/new discrimination. Indeed, there were reliable age differences in distinguishing identical from new items (Table 3), and in distinguishing identical items from both changed-expression and changed-expressionand-pose items (Table 5). Yet there were no statistically reliable age differences in distinguishing either type of old-but-changed item from entirely new faces (Table 4). This lack of age differences in changed/new discrimination cannot be attributed to insensitivity of the measure; changed/new discrimination, especially with changedexpression-and-pose items, was reliably greater in the multi-view condition than in the single-view condition. Instead, the findings imply that age differences in face memory pertain primarily to view-specific componentsdetails that distinguish different views of a face-rather than face-specific components-aspects common to different views of a face-in accordance with an adaptive-tradeoff view.

Although our findings supported the adaptive-trade-off view, there is an alternative account of why age differences vanished in the multi-view condition. Although the single-view and multi-view conditions used a constant presentation time of $12 \mathrm{sec}$ per face, the multi-view condition entailed varied repetition of each input item. Such varied repetition might remove age differences in remembering virtually all types of facial information. Due perhaps to age differences in motivational factors (varied repetition appearing more natural), habituationdishabituation effects (varied repetition maintaining attention), or sensitivity to effects of "encoding variability" (varied repetition producing differing encodings), elderly persons might perform more efficiently-relative to young adults-under varied-repetition conditions. Although this varied-repetition idea does not explain the pattern of age differences in the single-view condition, it seemed essential to determine whether it might account for the absence of age differences in the multi-view condition.

\section{EXPERIMENT 2}

The goal of Experiment 2 was to test the possibility that varied repetition, in and of itself, can remove age differences in face recognition. In pursuit of this goal, we employed a modification of the multi-view condition used in Experiment 1. This modification, which we will refer to as a multi-pose condition, involves varied repetition but also allows a type of view-specific feature to have high retrievability. As in the multi-view condition of Experiment 1 , each input face was shown in four poses. However, a critical difference was that expression stayed constant across these four poses. The subsequent test, which was simplified from Experiment 1, allowed assessment of identical/new, changed-expression/new, and identical/changed-expression discrimination (changedexpression-and-pose items were dropped from the test). ${ }^{3}$

Note that in the multi-view condition of Experiment 1, in which each input face was shown both smiling and with neutral expression, distinguishing identical from changedexpression items was virtually at the floor (Table 5). This was as expected, because in that condition identi$\mathrm{cal} /$ changed discrimination would have required a highly refined type of memory, that is, memory for the expression shown by one particular photograph (the threequarters photograph) of each face. In contrast, since the multi-pose condition of the present experiment involved showing each face with only one expression, there was no need to remember expressions of particular photographs. If the subject was able to retrieve the expression of any of the photographs of a face, or if she could retrieve the expression of some composite, schematic representation constructed from these input photographs, she could accurately judge whether the expression of a test item was changed. Hence, distinguishing identical from changedexpression items was expected to be much better than chance, eliminating floor effects.

Our main question was whether age differences in identical/changed-expression discrimination-previously absent in the multi-view condition-would be found in this multi-pose (but single-expression) condition in which overall performance should be reasonably high. If varied repetition is sufficient by itself to remove age differences in face memory, no age difference should be found. However, if the critical factor for observing age differences is whether or not recognition depends on viewspecific components of memory, young subjects should exceed the elderly at discriminating identical from changed-expression faces. To the extent that view-specific components are used in discriminating identical from new items, identical/new discrimination should show an age difference as well. Of course, changed/new discrimination, which depends on face-specific memory components, should show no age effect.

\section{Method}

The subjects were 19 young women (mean age $=27.2$, $S D=3.66$ ) and 17 elderly women (mean age $=66.5, S D=3.62$ ) who were recruited from a church group in Dallas, Texas. As in Experiment 1, a criterion for participation was (corrected) visual acuity of 20/40 or better in the best eye. Most of the younger women (79\%) but a minority of the elderly women $(29 \%)$ were college graduates. However, average vocabulary scores (second half of the WAIS) were comparable in the two age groups: the young group's mean was 23.8 out of $40(S D=7.80)$ and the elderly group's mean was 21.3 out of $40(S D=6.28)[t(34)=1.06, p>.10]$.

With the following exceptions, the design and materials were identical to those of the multi-view condition of Experiment 1. First, 
24 of the input faces were shown with smiling expressions in all four poses. The remaining 24 faces were shown with neutral expressions in all four poses. The assignment of face to type of expression was largely random, but missing or spoiled photographs dictated the assignment of several faces. Within each set of 24 faces, 12 were presented with one pose sequence (right-profile/right-threequarters/frontal/left-profile) and 12 were presented with the other (right-profile/frontal/left-three-quarters/left-profile). Finally, within each subset of 12 faces, 6 were tested as identical items and 6 were tested as changed-expression items (we did not use changedexpression-and-pose items). Which 6 faces were in each test condition was varied between subjects. For approximately half the subjects in each age group, the assignment of input face to type of test item (identical vs. changed-expression) was switched.

The procedure was unchanged from Experiment 1. The input task was to rate faces for pleasantness, and the test task was to judge each picture as "identical," "old-but-changed" (in expression only), or "new." There were equal numbers (24) of each item type, although this was not mentioned explicitly to subjects. Experimental sessions included 8 to 11 subjects.

\section{Results and Discussion}

The overall proportion of correct responses was .65 for the young group and .55 for the elderly group, representing a statistically reliable difference $[t(34)=4.33]$. These values were similar to those of the single-view condition of Experiment 1.

The mean proportions of "same" judgments and "old" judgments (i.e., 1 minus the proportions of "new" judgments) are shown in Table 6. Table 7 (Rows 1 and 2) shows the results of the signal-detection analysis. As in Experiment 1, there were two different types of identi$\mathrm{cal} /$ new discrimination (one based on "old"-judgment probabilities and the other on "same"-judgment probabilities), although we have collapsed these in the table. Since these two measures were again only moderately correlated $(r=60)$, we performed an ANOVA including measure as a factor. There was a main effect of type-ofmeasure $[F(1,34)=22.9, M S e=.001]$, as the $A^{\prime}$ s derived from "old" judgments (mean $=.90$ ) slightly exceeded those derived from "same" judgments (mean = .86). More importantly, the age main effect was significant $[F(1,34)=7.06, M S e=.005]$, and there was no interaction between age and type of measure.

Due to our dropping of changed-expression-and-pose items, there was only one type of changed/new discrimination and one type of identical/changed discrimination.

Table 6

Mean Proportions of "Old" and "Same" Judgments to Identical, Changed-Expression, and New Items in Each Age Group of Experiment 2

\begin{tabular}{|c|c|c|c|c|c|c|}
\hline \multirow[b]{3}{*}{ Age } & \multicolumn{6}{|c|}{ Judgment and Item-Type } \\
\hline & \multicolumn{3}{|c|}{ “Old" Judgments* } & \multicolumn{3}{|c|}{ "Same" Judgments } \\
\hline & Identical & $\begin{array}{c}\text { Changed } \\
\text { Expression }\end{array}$ & New & Identical & $\begin{array}{l}\text { Changed } \\
\text { Expression }\end{array}$ & New \\
\hline Young & .87 & .76 & $.16 \dagger$ & .59 & $.23 \dagger$ & $.03 \dagger$ \\
\hline Elderly & .93 & .87 & $.34 \dagger$ & .49 & $.37 \dagger$ & $.07 \dagger$ \\
\hline
\end{tabular}

*The proportions of "old" judgments shown in this table were derived by subtracting the proportions of "new" judgments from 1. †Proportions are false-alarm rates. All other proportions are hit rates.
Table 7

$A^{\prime}$ Scores for Identical/New, Changed-Expression/New, and Identical/Changed-Expression Discrimination in Experiment 2 and in the Single-View Condition of Experiment 1

\begin{tabular}{|c|c|c|c|}
\hline \multirow[b]{2}{*}{$\begin{array}{l}\text { Experiment } \\
\text { and Age }\end{array}$} & \multicolumn{3}{|c|}{ Measure } \\
\hline & $\begin{array}{c}\text { Identical/ } \\
\text { New }\end{array}$ & $\begin{array}{c}\text { Changed-Expression/ } \\
\text { New }\end{array}$ & $\begin{array}{c}\text { Identical/ } \\
\text { Changed-Expression }\end{array}$ \\
\hline \multicolumn{4}{|c|}{ Experiment 2} \\
\hline Young & .90 & .87 & .77 \\
\hline Elderly & $.86^{*}$ & .85 & $.61 \dagger$ \\
\hline \multicolumn{4}{|c|}{ Experiment 1 (Single-View) } \\
\hline Young & .91 & .86 & .78 \\
\hline Elderly & $.83^{*}$ & .80 & $.64 \dagger$ \\
\hline
\end{tabular}

Note-Experiment 2 employed multi-pose (but single-expression) presentation of faces at input. *Age difference gave $p<.02$ by ANOVA. †Age difference gave $p<.01$ by $t$ test.

As in the single-view condition of Experiment 1, the age effect on changed/new discrimination did not approach significance $[t(34)=1.27]$, whereas that on identi$\mathrm{cal} /$ changed discrimination was statistically robust $[t(34)$ $=5.33$ ]. For purposes of comparison, the lower two rows of Table 7 include corresponding $A^{\prime}$ s from the single-view condition of Experiment 1. Obviously, the pattern of age differences in the present multi-pose condition was similar to that in the previously used singleview condition. We conclude that this pattern of agerelated differences is obtainable under some types of varied-repetition conditions. We note finally that the conditional probability of a correct "identical" versus "oldbut-changed" judgment, given recognition of items as "old," was .69 and .55 for the young and elderly groups, respectively $[t(34)=3.63]$.

Age-of-face effects. Again we dichotomized the faces into young and old categories, and performed ANOVAs on the $A^{\prime}$ scores with face-age as a variable. Unlike Experiment 1 , in this case all three of the $A^{\prime}$ measures showed face-age $\times$ subject-age interactions $[F \mathrm{~s}(1,35)=$ $7.02,6.43$, and $7.84, M S$ es $=.003, .016$, and .004 , for identical/new, identical/changed, and changed/new scores, respectively]. However, in correspondence with Experiment 1, separate ANOVAs of the young-subject data showed main effects of face-age $[F(1,18)=10.3,11.7$, and 7.62, MSes $=.002, .010$, and .002 , respectively], whereas separate ANOVAs of the elderly-subject data did not. Collapsing the three $A^{\prime}$ measures, total scores for young subjects were significantly higher with young faces (.88) than old faces $(.82)[t(18)=4.95]$, whereas the total scores for elderly subjects were not significantly different for young faces $(.76)$ and old faces $(.79)[t(17)=1.70]$.

\section{GENERAL DISCUSSION}

The hypothesis examined in this research was that an adaptive trade-off favoring face-specific information at the expense of view-specific detail can account for age differences in face-picture memory. This adaptive tradeoff hypothesis made two essential claims: (1) the elderly have a general limitation in speed and/or efficiency of 
processing visual information, and (2) they compensate for this limitation when learning new faces by selectively encoding that type of information-abstract, face-specific information-most useful for recognizing faces in everyday life. The hypothesis predicted smaller age differences under multi-view conditions, in which face-specific information should be the main basis for performance, than under standard laboratory conditions, in which viewspecific information might play a larger role. It also predicted that under standard laboratory conditions, age differences should be largely restricted to measures reflecting memory for view-specific details (i.e., identi$\mathrm{cal} /$ new and identical/changed discrimination), as opposed to those reflecting memory for face-specific information (i.e., changed/new discrimination). The findings obtained in Experiment 1 supported both predictions. Furthermore, the findings obtained in Experiment 2 ruled out an alternative hypothesis - a varied-repetition hypothesis-for the first of these predictions.

The adaptive-trade-off hypothesis for age differences in face memory is consistent with information-processing conceptions of how memory for faces takes place. In particular, a recent model by Hay and Young (1982) holds that a diversified set of visual processes can occur upon encountering an unfamiliar face. These visual processes can be flexibly used to (1) create a new "recognition unit" (a logogen-like representation used for recognizing a familiar face regardless of view), and (2) analyze expression and other aspects of the face, linking to other cognitive processes. Viewed in the context of the Hay and Young model, the adaptive-trade-off hypothesis can be phrased as follows: Experiencing limits on speed and/or efficiency of visual processes, elderly subjects who are viewing new faces selectively deploy these visual processes, giving priority to forming new recognition units, at the expense of encoding expression and other view-specific aspects of the faces.

Although our findings supported an adaptive-trade-off hypothesis, they unavoidably were limited in several respects. Effects of age of face require more examination, particularly since these effects held more strongly for young than elderly subjects. This asymmetry in the interaction between age of subject and age of face may converge with other findings of sex of subject $x$ sex of face interactions (McKelvie, 1981), and race of subject $X$ race of face interactions (see Shepherd, 1981), both of which are sometimes asymmetric. An interpretation might be that whereas elderly subjects possess equivalent knowledge of the distinguishing features of young and old faces, young adults possess more knowledge of the distinguishing features of young faces. However, before accepting this or alternative hypotheses, it will be necessary to explore the effects of subject- and face-gender in conjunction with those of subject- and face-age (see McKelvie, 1981), and to perform more precise manipulations of degree of age-match between subjects and faces. In the present experiments, the average age of the elderly subjects (74 years in Experiment 1 and 68 years in Ex- periment 2) was much greater than that of many "old" faces (over half of the "old" faces were between 40 and 50 years old). This could explain why "old" and "young" faces were recognized similarly by elderly subjects. Furthermore, in Experiment 1, the age of the young sample (18 years) was younger than that of the youngest "young" faces (mid-20s). This might account for the complete absence of face-age effects with some measures in Experiment 1 (Experiment 2 used "young" subjects in their 20s and early 30s, and it showed face-age effects with all three measures). In any event, it is important to note that the critical findings of Experiment 1 -the reliable subject-age $\times$ condition interactions with identi$\mathrm{cal} /$ new and identical/changed $A^{\prime}$ s-were not qualified by face-age: Effects involving face-age in Experiment 1 were supported only with changed/new $A^{\prime}$ 's. And the main conclusion of Experiment 2-that varied repetition does not necessarily remove age differences-also is uncompromised by effects of age of face.

Another task for future research is to examine different subclasses of view-specific and face-specific information about faces. All the age differences that we observed here might pertain to a single type of view-specific detail: facial expression. Memory for expression obviously might contribute not only to identical/changed-expression discrimination, but also to identical/changed-expressionand-pose discrimination. Even identical/new discrimination, under conditions in which expression is memorable, might be based partly on expression-specific codes. Hence, given available data, it is arguable that age differences in memory for facial expression are the source of all age differences that we observed here. Indeed, it is arguable that they were the source of age differences obtained in prior face-memory experiments (Ferris et al., 1980; Smith \& Winograd, 1978).

Whether or not all age differences in face memory are reducible to age differences in remembering expression, the latter age differences are supported by our findings. This raises the question of whether age differences in remembering expression result from age differences in noticing expression at input. Fortunately, the pleasantness ratings suggest quite strongly that the answer is no. Table 8 shows average pleasantness ratings from the input phase of (1) the single-view condition of Experiment 1, and (2) the multi-pose (but single-expression) condition of Experiment 2. (Since the multi-view condition of Experiment 1 involved showing all faces with both expres-

Table 8

Mean Pleasantness Ratings by Young and Elderly Subjects to Smiling and Neutral Faces in Experiment 1 (Single-View Condition Only) and Experiment 2

\begin{tabular}{|c|c|c|c|c|}
\hline \multirow[b]{3}{*}{ Age Group } & \multicolumn{4}{|c|}{ Experiment and Expression } \\
\hline & \multicolumn{2}{|c|}{ Experiment 1} & \multicolumn{2}{|c|}{ Experiment 2} \\
\hline & Smiling & Neutral & Smiling & Neutral \\
\hline Young & 2.37 & 3.55 & 2.57 & 3.50 \\
\hline Elderly & 2.39 & 3.50 & 1.95 & 3.33 \\
\hline
\end{tabular}

Note-On the 5-point scale, $1=$ most pleasant and $5=$ least pleasant . 
sions, the ratings from that condition are irrelevant to whether subjects noticed expression.) The data have been broken down by expression of the faces (half were smiling and half had a neutral expression), and an effect of this factor is clear: The smiling faces were judged as more pleasant, and this effect was as strong with elderly subjects as it was with young adults (on the 5-point scale, 1 equaled most pleasant and 5 equaled least pleasant). ANOVAs performed on both sets of data showed highly significant expression effects $[F(1,30)=84.8, M S$ e $=$ .248 (Experiment 1, single-view), and $F(1,34)=63.7$, $M S$ e $=.377$ (Experiment 2)], which were not qualified by interactions with age $(p s>.10)$. There was an age main effect in Experiment $2[F(1,34)=8.04, M S e=$ .356], but the important point is that the two age groups showed equal sensitivity to facial expression in making their pleasantness ratings. Thus, age differences in identical/changed-expression discrimination imply age differences in mnemonic encoding and/or retrieval processes, not age differences in perceptually registering expression.

Although our data fit predictions of an adaptive-tradeoff hypothesis, alternative, post hoc accounts of our findings have yet to be evaluated. For example, it is arguable that retrieving view-specific details, such as facial expression, is more effortful than recognizing the "oldness" of faces (even old-but-changed faces), perhaps because retrieving view-specific details depends on active, "image-sampling" processes, as opposed to more passive familiarity processes (Gillund \& Shiffrin, 1984). This idea fits with assorted evidence for age differences in mental-imagery processes (Winograd \& Simon, 1980) and in effortful processes generally (Hasher \& Zacks, 1979). However, testing it adequately will demand ingenuity.

Another possible hypothesis is that age differences in face-picture memory, like age differences in many verbal memory tasks, reflect age differences in some aspect of categorical, semantic processing (Craik \& Simon, 1980; Duchek, 1984; Till \& Walsh, 1980). In order to tie this notion to our findings, it might be argued that some types of view-specific details, specifically those of facial expression, can influence semantic categorization of faces. Klatzky et al. (1982) point out that categorizing faces by occupational stereotype might be based partly on affective properties. And certainly expression is one such property (whether a face evokes the category of "undertaker" might obviously depend upon facial expression). This leads to the suggestion that memory for expression is partly based on memory for occupational (or other) categories, and that age differences in categorical processing explain age differences in distinguishing identical-copy items from changed-expression and other item types. Although this categorical-processing hypothesis obviously is speculative, it makes a clear-cut prediction: Since pose is less likely than facial expression to affect how a face is semantically categorized, age differences in distinguishing identical items from changed-pose-but-sameexpression items (not examined in the present research) should be relatively slight. However, given that with other types of visual stimuli there are age differences in remembering such "nonmeaningful" attributes as left-right orientation (Bartlett et al., 1983), we are inclined to doubt this prediction will hold.

The theoretical questions that are raised by our data do not qualify two main points: First, age differences in discriminating identical from new faces were eliminated in a relatively naturalistic condition of processing multiple views of faces with facial expression varying (Experiment 1). Second, the pattern of age differences in a singleview condition, and also in a modified multi-pose condition with facial expression constant, supported a deficit in remembering expression (Experiments 1 and 2) and possibly pose (Experiment 1). These findings converge with those of Yarmey and Kent (1980) in bearing a practical implication for eyewitness testimony: Despite age differences in memory for photographs of faces, elderly witnesses might identify a suspect with high reliability, especially if they originally experienced more than a single view.

\section{REFERENCES}

ARENBERG, D. (1977). The effects of auditory augmentation on visual retention for young and old adults. Joumal of Gerontology, 32, 192-195.

Bartlett, J. C., Hurry, S., \& Thorley, W. (1984). Typicality and familiarity of faces. Memory \& Cognition, 12, 219-228.

Bartlett, J. C., Till, R. E., Gernsbacher, M., \& Gorman, W. (1983). Age-related differences in memory for lateral orientation. Journal of Gerontology, 38, 439-446.

BARTlett, J. C., Till, R. E., \& LeVy, J. C. (1980). Retrieval characteristics of complex pictures: Effects of verbal encoding. Joumal of Verbal Learning \& Verbal Behavior, 19, 430-449.

BruCE, V. (1982). Changing faces: Visual and non-visual coding processes in face recognition. British Journal of Psychology, 73, $105-116$.

Bruce, V. (1983). Recognizing faces. Philosophical Transactions of the Royal Society of London, B 302, 423-436.

ChanCE, J. E., \& Goldstein, A. G. (1976). Recognition of faces and verbal labels. Bulletin of the Psychonomic Society, 7, 384-386.

CoHen, G. (1979). Language comprehension in old age. Cognitive Psychology, 11, 412-429.

CraIK, F. I. M. (1977). Age differences in human memory. In J. E. Birren \& K. W. Schaie (Eds.), Handbook of the psychology of aging. New York: Van Nostrand Rinehold.

Craik, F. I. M., \& Simon, E. (1980). Age differences in memory: The roles of attention and depth of processing. In L. W. Poon, J. L. Fozard, L. S. Cermak, D. Arenberg, \& L. W. Thompson (Eds.), New directions in memory and aging: Proceedings of the George Talland Memorial Conference. Hillsdale, NJ: Erlbaum.

Davies, G., Ellis, H., \& ShePherd, J. (Eds.). (1981). Perceiving and remembering faces. New York: Academic Press.

DuCHEK, J. M. (1984). Encoding and retrieval differences between young and old: The impact of attentional capacity usage. Developmental Psychology, 20, 1173-1180.

DukEs, W. F., \& BEVAN, W. (1967). Stimulus variation and repetition in the acquisition of naming responses. Journal of Experimental Psychology, 74, 178-181.

Ferris, S. H., Crook, T., Clark, E., McCarthy, M., \& Rae, M. (1980). Facial recognition memory deficits in normal aging and senile dementia. Journal of Gerontology, 35, 707-714

Gibson, E. J., \& SPeLKe, E. S. (1983). Perception. In P. H. Mussen (Ed.), Handbook of child psychology (pp. 1-76). New York: Wiley. GilluND, G., \& Shiffrin, R. M. (1984). A retrieval model for both recognition and recall. Psychological Review, 91, 1-67. 
Goldstein, A. G., Johnson, K. S., \& Chance, K. E. (1979). Does fluency of face description imply superior face recognition? Bulletin of the Psychonomic Society, 13, 15-18.

GRIER, J. B. (1971). Nonparametric indexes for sensitivity and bias: Computing formulas. Psychological Bulletin, 75, 424-429.

GutTentaG, R. E. (1985). Memory and aging: Implications for theories of memory development during childhood. Developmental Review, 5, 56-82.

HASHER, L., \& ZACKS, R. T. (1979). Automatic and effortful processes in memory. Journal of Experimental Psychology: General, 108, 356-388.

HaY, D. C., \& Young, A. W. (1982). The human face. In A. W. Ellis (Ed.), Normality and pathology in cognitive functions. London: Academic Press.

KAUSLER, D. H., \& PucketT, J. M. (1981). Adult age differences in memory for sex of voice. Journal of Gerontology, 36, 44-50.

KlatzKy, R. L. (1983a, August). Facial categories: How visual? How abstract? Paper presented at the meeting of the American Psychological Association, Anaheim, CA.

KLATZKY, R. L. (1983b). Visual memory: Definitions and functions In R. Wyer, T. Srull, \& J. Hartwick (Eds.), Handbook of social cognition. Hillsdale, NJ: Erlbaum.

Klatzky, R. L., \& ForRest, F. H. (1984). Recognizing familiar and unfamiliar faces. Memory \& Cognition, 12, 60-70

Klatzky, R. L., Martin, G. L., \& Kane, R. A. (1982). Semantic interpretation effects on memory for faces. Memory \& Cognition, 10 , 195-206.

LABouvie-VIEF, G., \& SchelL, D. A. (1982). Learning and memory in later life. In B. B. Wolman (Ed.), Handbook of developmental psychology. Englewood Cliffs, NJ: Prentice-Hall

Light, L. L., ZELINSKI, E. M. (1983). Memory for spatial information in young and old adults. Developmental Psychology, 19, 901-906.

McKelvie, S. J. (1981). Sex differences in memory for faces. Journal of Psychology, 107, 109-125.

Park, D. C., Puglisi, J. T., \& Sovacool, M. (1983). Memory for pictures, words, and spatial location in older adults: Evidence for pictorial superiority. Journal of Gerontology, 38, 582-588.

Perlmutter, M. (1980). An apparent paradox about memory aging. In L. W. Poon, J. L. Fozard, L. S. Cermak, D. Arenberg, \& L. W Thompson (Eds.), New directions in memory and aging: Proceed ings of the George Talland Memorial Conference. Hillsdale, NJ: Erlbaum.

Perlmutter, M., \& Mitchell, D. B. (1982). The appearance and disappearance of age differences in adult memory. In F. I. M. Craik \& S. Trehub (Eds.), Aging and cognitive processes. New York: Plenum Press.

Petros, T., Tabor, L., Cooney, T., \& Chabot, R. J. (1983). Adult age differences in sensitivity to semantic structure of prose. Developmental Psychology, 19, 907-914.

Pezdek, K. (1983). Memory for items and their spatial locations by young and elderly adults. Developmental Psychology, 19, 895-900.

Pezdek, K., \& Evans, G. (1979). Visual and verbal memory for objects and their spatial locations. Journal of Experimental Psychology: Human Learning \& Memory, 5, 360-373.

Poon, L. W. (1985). Differences in human memory with aging: Nature, causes, and clinical implications. In J. E. Birren \& K. W. Schaie (Eds.), Handbook of the psychology of aging. New York: Van Nostrand Rinehold.

RIEGE, W. H., \& INMAN, V. (1981). Age differences in nonverbal memory tasks. Journal of Gerontology, 36, 51-58.

Rogoff, B., Gauvain, M., \& Ellis, S. (1984). Development viewed in its cultural context. In M. H. Bornstein \& M. E. Lamb (Eds.), Developmental psychology: An advanced textbook. Hillsdale, NJ: Erlbaum.

SALthouse, T. A. (1980). Age and memory: Strategies of localizing the loss. In L. W. Poon, J. L. Fozard, L. S. Cermak, D. Arenberg, \& L. W. Thompson (Eds.), New directions in memory and aging. Proceedings of the George Talland Memorial Conference. Hillsdale, NJ: Erlbaum.

SHEPHERD, J. (1981). Social factors in face recognition. In G. Davies, H. Ellis, \& J. Shepherd (Eds.), Perceiving and remembering faces. London: Academic Press.

Smith, A. D., \& WinOGRAD, E. (1978). Adult age differences in remembering faces. Journal of Gerontology, 14, 443-444.

Till, R. E., Bartlett, I. C., Doyle, A. (1982). Age differences in picture memory with resemblance and discrimination tasks. Experimental Aging Research, 8, 179-184.

TILL, R. E., \& WALSH, D. A. (1980). Encoding and retrieval factors in adult memory for implicational sentences. Joumal of Verbal Learning \& Verbal Behavior, 19, 1-16.

Warrington, E. K., ACKroyd, C. (1975). The effect of orienting tasks on recognition memory. Memory \& Cognition, 3, 140-142.

WINOGRAD, E., \& SIMON, E. W. (1980). Visual memory and imagery in the aged. In L. W. Poon, J. L. Fozard, L. S. Cermak, D. Arenberg, \& L. W. Thompson (Eds.), New directions in memory and aging: Proceedings of the George Talland Memorial Conference. Hillsdale, NJ: Erlbaum.

YARMEY, A. D., \& KENT, J. (1980). Eyewitness identification by elderly and young adults. Law \& Human Behavior, 4, 359-371.

Zelinski, E. M., GilewsKI, M. J., \& Thompson, L. W. (1980). Do laboratory tests relate to everyday remembering and forgetting? In L. W. Poon, J. L. Fozard, L. S. Cermak, D. Arenberg, \& L. W. Thompson (Eds.), New directions in memory and aging: Proceedings of the George Talland Memorial Conference. Hillsdale, NJ: Erlbaum

\section{NOTES}

1. Although the verbal intelligence of the high-school seniors was slightly less than that of the elderly subjects, this difference-if it matters at all-would work against our prediction of a young-subject advantage with some of our measures. So too would the fact that the young subjects' ages were slightly less than those of the youngest experimental faces, which might have reduced their tendency to "identify" with these faces (see McKelvie, 1981). Note that the young subjects used in Experiment 2 (1) were in their 20s and (2) did not differ from the elderly in vocabulary. Yet the results of this study converged nicely with those of the single-view condition of Experiment 1 (Table 7).

2. Prior research on scene recognition has shown that independent variables (verbal coding) can have differing effects on identical/new discrimination based on "same" judgments versus "old" judgments (Bartlett et al., 1980). It was for this reason, as well as the moderate correlation between the two identical/new scores, that type of measure was treated as a factor in the ANOVA.

3. We note that in the present design, it is questionable whether facial expression is properly termed a "view-specific" aspect of faces In a strictly methodological sense, expression is not view-specific, since we held it invariant over input poses. But in a broader, ecological sense, expression is view-specific, since it ordinarily changes across poses in real life. Although here we adopt the ecological view in calling expression a view-specific component, the issue is not critical to the question of whether varied repetition removes age differences. 